\title{
Performance Evaluation of Basic Medical Insurance Fund for Urban Workers in Jiangsu Province
}

\author{
Juan $\mathrm{Du}^{1}$ \\ ${ }^{1}$ College of Economic and Management, Nanjing University of Aeronautics and Astronautics, Nanjing, China \\ Correspondence: Juan Du, College of Economic and Management, Nanjing University of Aeronautics and \\ Astronautics, Nanjing, 211106, China. Tel: 86-156-0518-6035. E-mail: dj19930809@163.com
}

Received: March 22, 2017

Accepted: April 14, 2017

Online Published: May 15, 2017

doi:10.5539/ijef.v9n6p133

URL: https://doi.org/10.5539/ijef.v9n6p133

\begin{abstract}
As a significant part of social security system, basic medical insurance guarantees the sustainable development of society. With aged trend of population in China, a series problems are exposed with increasing demand of fund, which lead to serious financial risk. As a result, it is emergent to evaluate whether the management of basic medical insurance fund is efficiency or not. Hence, this article attempts to construct a performance evaluation index system and apply it to assess the management of basic medical insurance fund for urban workers in Jiangsu Province, including its raising, operating, investing and paying under the guidance of balanced scorecard.
\end{abstract}

Keywords: basic medical insurance fund, performance evaluation, balanced scorecard, analytic hierarchy process, urban workers

\section{Introduction}

\subsection{Introduction of Performance Evaluation of Baisc Medical Insurance Fund for Urban Workers}

Basic medical insurance fund is the economic fundation of basic medical insurance. It is closely related to the vital interests of the public. Therefore, efficient management of the basic medical insurance fund is very important for social stability and development. However, there are some problems gradually. With population aging, basic medical insurance fund will not be able to meet the needs of its expenditure by 2024. Effective management can greatly reduce the financial pressure and avoid the social and economic crisis of medical expenses. In addition, for government, to understand if the basic medical insurance fund is able to meet the needs of the public or not is very important for policy making. To solve such problems, we need to establish a comprehensive and scientific evaluation index system of the basic medical insurance fund and evaluate its collection, operation and payment. This paper takes basic medical insurance fund for urban workers in Jiangsu province for example.

In Jiangsu province, human resources and social security department takes charge of medical fund for urban workers. And the provincial medical insurance center is mainly responsible for collecting data, preparing budget and financial statements with the operation of the fund. By this way, the center hope to maintain and appreciate the amount of fund.

Basic medical insurance system for urban workers in Jiangsu Province has been lasting for twenty years. During this period, basic medical insurance system for urban worker in Jiangsu province has been greatly developed. As of the end of 2014, number of insured almost reached 23.6 million, compared with number of urban employment, the insured rate reached $76.49 \%$. In the expansion of the coverage, the contradictions and problems in the fund management have been exposed. Under dual pressures of population aging and inflation, sustainability of the fund has received extensive attention. Compared with the other social insurance fund management, medical insurance has more unstable factors. Insured persons usually occur in a small amount of expenditure, but once suffering from disease, they have to spend a large sum of expenses. And with development of population aging, the incidence of the disease will gradually increase. Therefore, it is particularly important to pay attention to fund operation efficiency, supervision and management, and so on.

At the beginning of 2011, the Jiangsu Audit Office issued and implemented the "general operation guidelines for the audit performance audit in Jiangsu province" as well as seven specific guidelines to provide the basis and 
guidance for the relevant performance auditing work. When designing the evaluation indicators of performance audit of the social insurance fund, the Jiangsu audit office pay great attention to its ability to preserve and increase the value and benefits of the use. When design evaluation system, they follow the $3 \mathrm{E}$ principle of economy, efficiency and effectiveness and analyze four aspects separately, including the investment, process, output and result of the fund. However, government has not yet been able to implement comprehensive performance audit. The audit of the social insurance fund is still mainly confined to financial audit. In addition, audit process based on 3E principle is often easy to ignore the public's satisfaction indicators and pursues low cost. In the principal-agent relationship, the principal pays attention not only to the economy, efficiency and effectiveness of the social insurance fund, but also to the fairness, the service and the environment. Therefore, I think that $3 \mathrm{E}$ principle are unable to meet the expectations of the public, and it is expected to construct a performance evaluation index system which is more diversified and hierarchical.

\subsection{Overview of Ralated Study}

For designing the medical insurance fund performance evaluation index system, Yan Ma (2006) proposed that the system should include both process performance and result performance. It should compare the forming processes with actual results of the government's management. In the evaluation of the performance of the fund's expenditure, Ning Yu (2012) pointed out that the system should be composed of two parts: basic index and evaluation index. Yun Lu (2013) put forward the need to pay attention to non-financial indicators, to enhance endogenous motivation, and focus on sustainable development. Hongxiang Fu (2013) proposed that the most important to establish the system is to choose key performance indicators, and to further analyze the concept, basis and practical significance of every key performance indicator.

Regarding process of performance evaluation, Yan Cheng (2010) believe that performance evaluation should be carried out in accordance with the following six procedures: drawing up a plan, establishing an organization, constructing the index, collecting relative information, choosing the method and writing the report. Chuanjie Yang (2010) formed a comprehensive system of performance evaluation system framework covering the theory of social insurance fund performance evaluation and the establishment of the index system.

In Germany, disease fund is supervised both by federal and state authorities. The supervision process is mainly divided into three parts, including information collection, evaluation and communication adjustment. Germany's performance audit is very comprehensive, each supervision departments has a separate performance audit. In the evaluation process, indicators will be clearly defined. Finally, they will give advice on how to make the fund run more efficiently in the process of communication (Bärnighausen \& Sauerborn, 2002).

Management of social security fund in the United States is relatively complex in the world. The social security system in America has been lasting for more than 100 years. SSA (social security administration) is mainly responsible for management of the social security trust fund and the general fund. Combined with budgeting (Maarse, Paulus, \& Kuiper, 2005), performance evaluation process mainly has the following processes. Firstly, set task. It is summarized with four aspects (Zhang \& Ding, 2007), including quality of service, plan management, debt paying ability and human resource and develop them into long-term goals. Secondly, decompose long-term goals into short-term goals, that is, performance goals. Finally, SSA will provide annual performance evaluation report, in which compares the performance objectives with the actual results, sums up the experience and lessons, and adjusts the next year's performance plan combined with environmental changes and other factors (Posner, 2003).

In summary, the research at home and abroad mainly has the following characteristics. First of all, research on the management performance evaluation of basic medical insurance fund for urban workers in China is few, and needs to be further improved. The performance evaluation index system has not been formed in our country at present, so we always lack adequate theoretical support in the process of measuring the index design. And because lack of consistent evaluation criteria, a large number of basic data can't be collected. At present, the research on the performance evaluation of the social insurance fund or the medical insurance fund in our country mostly stays in the theoretical knowledge, which is lack of empirical analysis. Second, the current social security fund management in the United States, Germany and other countries is relatively mature, and complete performance evaluation system has already been constructed with its own characteristics. It provides great reference significance for our country's medical insurance fund performance evaluation.

\section{Method}

BSC (balanced scorecard) (Yan, Bai, \& Lin, 2004) is a new method of performance evaluation by measuring finance, customer, internal process and ability of learning and development all four dimensions. 


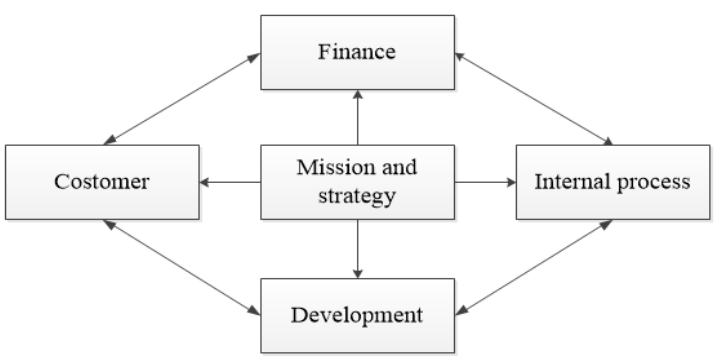

Figure 1. Basic framework of BSC

\subsection{Identify Mission and Strategy}

The mission of management of basic medical insurance fund for urban workers is to ensure the basic medical is available for all urban workers.

\subsection{Determine the Objectives of Each Dimension}

Finance dimension objectives: to solve the economic problems of basic medical insurance fund management. The key factor of the financial performance evaluation is the fund's ability to reach the balance of payments, as well as the income rate of the fund investment can be achieved under the premise of ensuring the security of the fund (Lin, 2007). Balance between fund revenue and expenditure is the most important condition for sustainable development.

Public dimension objectives: this paper transformed customer dimension into the public dimension (Guo, 2013). Public dimension of performance evaluation is mainly focused on basic medical insurance coverage of urban workers, the premium burden and the insured person's benefit.

Internal management dimension objectives: the internal process dimension is mainly to measure the efficiency of the enterprise (Sun, 2013). Therefore, for performance evaluation of basic medical insurance fund management of urban employees, internal process dimensions can be transformed into the internal management of social insurance agencies, medical insurance agencies, etc. Performance evaluation of this dimension is mainly to improve the efficiency of management, reduce the management cost, improve the operation process, supervise the medical service providers and control the investment risk.

Dimension of learning and development objectives: in order to cope with the pressure of population aging and inflation, we must improve sustainable growth ability and management ability of the basic medical insurance fund for urban workers (Rong, 2014). Through the cultivation of talent team, the construction of information technology, we hope to achieve the expansion of the basic medical insurance fund and improve the quality of funds (Liu, 2014).

\subsection{Determine and Calculate the Specific Evaluation Index}

Through determining each dimension and its objectives, we can design the following key indicators:

Table 1. Key indicators for each dimension

\begin{tabular}{|c|c|c|}
\hline Dimension & First class indicator & Second class indicator \\
\hline \multirow[t]{5}{*}{ Finance (B1) } & balance of payments $(\mathrm{C} 1)$ & total amounts of funds receive(D1) \\
\hline & & total amount of funds spending(D2) \\
\hline & & fund surplus rate(D3) \\
\hline & security (C2) & fund balance rate (D4) \\
\hline & profitability (C3) & investment return rate(D5) \\
\hline \multirow[t]{4}{*}{ Public (B2) } & coverage $(\mathrm{C} 4)$ & insured rate(D6) \\
\hline & & growth rate of the insured population(D7) \\
\hline & premium burden $(\mathrm{C} 5)$ & $\begin{array}{l}\text { per capita amount of insurance premium accounted for proportion of the } \\
\text { average wage of urban workers (D8) }\end{array}$ \\
\hline & assurance level (C6) & $\begin{array}{l}\text { basic medical insurance premium accounted for the proportion of total } \\
\text { health care costs(D9) }\end{array}$ \\
\hline \multirow[t]{3}{*}{ Internal process (B3) } & management efficiency (C7) & management cost ratio(D10) \\
\hline & & growth rate of return on investment(D11) \\
\hline & information disclosure level (C8) & number of open government information(D12) \\
\hline
\end{tabular}




\begin{tabular}{lll}
\hline $\begin{array}{l}\text { Ability to learn and } \\
\text { develop (B4) }\end{array}$ & growth rate of the insured population(D13) \\
& proportion of retirement in service(D14) \\
& fund balance growth rate(D15) \\
& rate of return on investment- rate of inflation(D16) \\
\hline
\end{tabular}

\subsection{Set Weight Coefficient}

Different weight coefficients will reflect preference for different indicators and lead to different evaluation results (Zhu \& Cheng, 2008). AHP (analytic hierarchy process) is consistent with the three level index system established in paper. Therefore, I will use AHP to set the weight of each layer. The application of AHP can be divided into the following four steps (Xu, 2011).

\subsubsection{Establish Hierarchical Structure Model}

In the process of establishing the model, we must first thoroughly analyze the problem, determine the system goal, and then divide it into different elements layer by layer, in this way we can form a comprehensive evaluation index system.

The mission of basic medical insurance fund performance evaluation system is set as the first layer, as the A layer. The finance, public dimension, internal process and the ability to learn and develop dimensions as the element layer is the B layer. Index under the dimensions form the $\mathrm{C}$ and $\mathrm{D}$ layers, as shown in the table 1 above.

\subsubsection{Construct Judgment Matrix}

The second step is to construct the judgment matrix. From the beginning of the second level, the indicators of same level have to be compared in pairs to determine their importance according to their different influence on the upper layer. This step is crucial in the combination of qualitative and quantitative analysis.

There we will use method of nine-scale proposed by T. L. Saaty professor to compare elements in pairs. 1, 3, 5, 7 and 9 represent equally importance, moderately more importance, strongly more importance, very strongly importance and extremely importance, respectively.

Table 2. Judgement matrix for B layer

\begin{tabular}{lllll}
\hline Performance evaluation & Finance (B1) & Public (B2) & Internal process(B3) & Ability to learn and develop(B4) \\
\hline Finance(B1) & 1 & 2 & 3 & 5 \\
Public(B2) & $1 / 2$ & 1 & 4 & $9 / 2$ \\
Internal process(B3) & $1 / 3$ & $1 / 4$ & 1 & 3 \\
Ability to learn and develop(B4) & $1 / 5$ & $2 / 9$ & $1 / 3$ & 1 \\
\hline
\end{tabular}

After constructing the matrix, we will use the method of ANC to calculate the importance coefficient of each element. Take the B layer for example, the importance coefficient of each element are calculated as $0.45,0.337$, 0.145 and 0.068 .

\subsubsection{Test Consistency of Matrix}

The matrix need meet three general conditions of non-negativity, reflexivity and reciprocity. So we have to conduct the basic consistency test, including consistence index and random consistency index test.

The maximum eigenvalue of matrix is:

$$
\lambda_{\max }=\frac{1}{n} \sum_{i=1}^{n} \frac{\left(B_{\omega}\right)_{i}}{\omega_{i}}
$$

Consistence index is calculated as the equation (2):

$$
\text { C.I. }=\frac{\lambda_{\max }-n}{n-1}
$$

Random consistency index can be searched from the Table 3 according to number of the matrix dimension.

Table 3. Random consistency index

\begin{tabular}{lllllllll}
\hline $\mathrm{N}$ & 3 & 4 & 5 & 6 & 7 & 8 & 9 & 10 \\
\hline R.I. & 0.58 & 0.89 & 1.12 & 1.24 & 1.32 & 1.41 & 1.45 & 1.49 \\
\hline
\end{tabular}


Consistence ratio is equal to divide consistence index by random consistency index. If consistence ratio is less 0.1 , we can believe the matrix meets the requirements.

\subsubsection{Calculate Importance Coefficient for All Element}

After the consistency test, we can carry on the fourth step, to calculate the importance coefficient of each element to the system goal. We reach the following weight table of evaluation index through calculation.

Table 4. Weight of evaluation index

\begin{tabular}{|c|c|c|c|c|c|}
\hline \multicolumn{2}{|c|}{ Dimension } & \multicolumn{2}{|c|}{ First class indicator } & \multicolumn{2}{|c|}{ Second class indicator } \\
\hline \multirow{5}{*}{ B1 } & \multirow{5}{*}{0.450} & & & D1 & 0.105 \\
\hline & & $\mathrm{C} 1$ & 0.280 & D2 & 0.105 \\
\hline & & & & D3 & 0.070 \\
\hline & & $\mathrm{C} 2$ & 0.108 & D4 & 0.108 \\
\hline & & $\mathrm{C} 3$ & 0.062 & D5 & 0.062 \\
\hline \multirow{4}{*}{ B2 } & \multirow{4}{*}{0.337} & \multirow{2}{*}{$\mathrm{C} 4$} & \multirow{2}{*}{0.150} & D6 & 0.038 \\
\hline & & & & D7 & 0.112 \\
\hline & & C5 & 0.108 & D8 & 0.108 \\
\hline & & C6 & 0.079 & D9 & 0.112 \\
\hline \multirow{4}{*}{ B3 } & \multirow{3}{*}{0.145} & \multirow{2}{*}{$\mathrm{C} 7$} & \multirow{2}{*}{0.109} & D10 & 0.022 \\
\hline & & & & D11 & 0.087 \\
\hline & & $\mathrm{C} 8$ & 0.036 & D12 & 0.036 \\
\hline & \multirow{4}{*}{0.068} & \multirow{4}{*}{ C9 } & \multirow{4}{*}{0.068} & D13 & 0.017 \\
\hline \multirow{3}{*}{ B4 } & & & & D14 & 0.005 \\
\hline & & & & D15 & 0.011 \\
\hline & & & & D16 & 0.035 \\
\hline
\end{tabular}

\section{Results}

Some of the selected index are the bigger the better, and some are the lower the better, therefore, we need to reverse the contrary index firstly. In addition, because the unit of the index is not the same, that is, there are different dimensions, therefore, the data of these index should be non-dimensional to facilitate comparison.

After making index positive and non-dimensional, we can reach the following table that show the processed data about performance evaluation index of medical insurance fund for urban workers in Jiangsu province from 2010 to 2014 .

Table 5. Processed data of performance evaluation index

\begin{tabular}{llllll}
\hline Second class index & 2010 & 2011 & 2012 & 2013 & 2014 \\
\hline D1 & -0.841 & -0.449 & 0.218 & 1.110 & 1.757 \\
D2 & 2.150 & 1.837 & 1.286 & 0.629 & 0.00 \\
D3 & -0.390 & -0.391 & -0.407 & -0.372 & -0.435 \\
D4 & 1.689 & 1.689 & 1.689 & 1.689 & 1.689 \\
D5 & -0.832 & -0.808 & -0.782 & -0.802 & -0.801 \\
D6 & 0.839 & 0.793 & 0.907 & 1.002 & 1.074 \\
D7 & -0.769 & -0.701 & -0.695 & -0.741 & -0.783 \\
D8 & 0.002 & 0.006 & 0.006 & 0.000 & 0.005 \\
D9 & 1.100 & 1.176 & 1.187 & 1.218 & 1.247 \\
D10 & 0.404 & 0.354 & 0.000 & 0.380 & 0.364 \\
D11 & -0.832 & -0.808 & -0.782 & -0.802 & -0.801 \\
D12 & 1.779 & -0.519 & -0.268 & -0.454 & -0.538 \\
D13 & 1.847 & 1.915 & 1.921 & 1.875 & 1.834 \\
D14 & 0.000 & 0.029 & 0.055 & 0.045 & 0.032 \\
D15 & -0.422 & -0.435 & -0.428 & -0.363 & -0.455 \\
D16 & -0.669 & -0.914 & -0.835 & -0.732 & -0.801 \\
\hline
\end{tabular}


Then we multiply the above standardized data by the relevant weight listed in table 5 , so we can obtain the final result of the performance evaluation of basic medical insurance fund management for urban workers in Jiangsu province from 2010 to 2014.

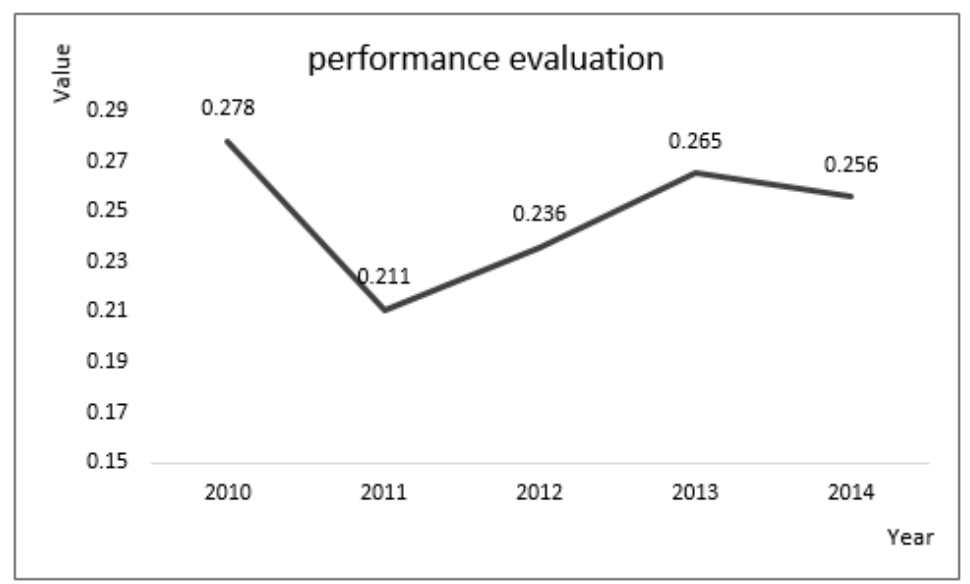

Figure 2. Result of performance evaluation from 2010 to 2014

As can be seen from the above figure, the management performance of basic medical insurance fund for urban workers in Jiangsu province began to rise from 2011, and declined from 2013. We can sum up the following three reasons for this phenomenon.

Firstly, fund raised can't cover the expenditure, which result in a substantial decline in fund's balance rate. The increase in total expenditure of fund, mainly due to the increase of medical expenses, including outpatient expenses and hospitalization expenses.

Secondly, the type of fund investment is so less (only government bonds and bank deposits). Due to all the fund investment is robust, it limits the growth of fund's investment yield.

Lastly, the growth rate of number of insured persons is decreased. The main reason for the sharp decline in the growth rate of the insured population is that with the coverage of basic medical insurance system for urban workers gradually expanded and close to saturation. Therefore, the government has to take measures to raise more fund in different ways.

\section{Discussion}

To solve these problems, the paper proposes several suggestions from four dimensions of BSC as followed.

\subsection{Finance Dimension}

The first is to control medical expenses. The budget management should be further strengthened. At the same time, we should encourage the local government to reform medical insurance agencies and medical service providers' negotiation mechanism and payment way, reasonably determine the standard of medicine, medical services and control costs and expenses. In addition, we should constantly update and improve the medical insurance information system, and monitor the behavior of medical services, thereby reducing the unreasonable medical expenses and preventing the occurrence of medical fraud.

Second, basic medical insurance for urban workers is expected to expand coverage, such as covering the self-employed and migrant workers. By increasing number of the insured person, disease risk can be better shared.

Third, in order to resist pressure of inflation, fund's investment should adopt diversified portfolios, as far as possible to expand investment channels, and balance the security, liquidity and profitability of fund. For example, in accordance with the provisions, more than $50 \%$ of the investment can be bank deposits and national bonds, to achieve the purpose of controlling risk. At the meanwhile, a certain proportion of funds also can be invested in relatively high yield of stocks or industrial and so on, to improve the income.

\subsection{Public Dimension}

First, considering the fairness of fund raising, we can distinguish the employers and employees required 
collection ratio according to the type and size of the enterprise. In addition, premium can also be based on the individual's annual income level. Also with the growth of the age, health care costs will gradually increase. Therefore, the premium collection rate can be divided according to the age. In this way, not only can increase the fund raised, but also can take into account the fairness to reduce premium pressure for the low income crowd.

Second, as the fund's principal, the real holder, the public should fully participate in the management of the fund. According to the government publicity information, the public should clear the fund's collection, operation and payment, and put forward management suggestions and opinions in order to get better medical services.

\subsection{Internal Process Dimension}

The medical insurance agency is responsible for collection, management and payment of medical insurance fund. Fund raising is the beginning of the operation of fund and determines the size of fund whether can meet the needs of adequate response or not. Therefore, in this part, medical insurance agencies should strengthen internal management, and follow the relevant laws and regulations, standardize the financing behavior and give severe punishment if violate. For fund management, allocate the assets in safety, improve the management efficiency, and strengthen risk assessment and management. Fund should be earmarked, combined with system account, in this way to prevent misuse and corruption.

As the top management of social agencies, the ministry of human resources and social security is responsible for the formulation of management policy. Therefore, this section should definite the content of supervision, develop and improve the relevant policies and regulations to regulate fund management, and clear punishment system. At the same time, public supervision should be strengthened with further improving the information disclosure mechanism, including the fund balance of payments, investment, distribution, etc.

\subsection{Ability to Learn and Develop Dimension}

To ensure the sustainability of fund, first of all, we should strengthen the medical insurance fund management efficiency, optimize the management process and improve the allocation capacity of funds. Meanwhile, measures like strengthening the training of employees and enhancing the proportion of high quality staff can be taken to adapt to changes in economic development.

Faced with some uncontrollable factors, such as major epidemic disease, aging peak, and so on, it is difficult to take measures to make the fund balance. Therefore, we can establish a special fund to cope with the risk, to promise the balance of payments and relieve financial pressure. During the process of operation of the fund, we can establish the early warning system. In this way, not only to be able to predict and remind when the fund overspend so that we can implement measures to deal with in time, but also to provide data for health insurance agencies and other regulatory agencies in need, help to develop and further improve the relevant policies.

At present, the hospital income increases with the increase of the service item and the length of hospital stay. This approach tends to increase moral hazard. In the case of asymmetric information, doctors often induce excessive medical treatment, resulting in a waste of medical resources and unreasonable growth of fund expenditures. Therefore, it is necessary to establish a reasonable fund payment way. Fees can be charged according to the type of disease, so that the chance of a doctor induced by excessive medical treatment can be effectively reduced.

\section{Acknowledgments}

This work was supported by the humanity and social science project organized by ministry of education (14YJA630096).

\section{References}

Bärnighausen, T., \& Sauerborn, R. (2002). One hundred and eighteen years of the german health insurance system: Are there any lessons for middle- and low-income countries? Social Science \& Medicine, 54(10), 1559-87. http://doi.org/10.1016/S0277-9536(01)00137-X

Fu, H. X., \& Chen, W. (2013). The conception of performance evaluation index of medical insurance fund management. China Health Insurance, 9, 33-36.

Guo, L. P. (2013). The discussion of China's social insurance fund performance audit evaluation system. Doctoral dissertation, Shanxi University of Finance and Economics.

Li, R. (2014). Study on the construction of performance evaluation index system of basic pension insurance fund. Doctoral dissertation, Shandong University of Finance and Economics.

Lin, Y. (2007). The management of social insurance fund. Beijing, BJ: China Labor Publishing House. 
Liu, W. B. (2013). Evaluation of pension fund investment performance based on DEA analysis. Social Security Research, (2), 90-96.

Lu, Y., \& Zhou, M. H. (2013). Performance evaluation of the social medical insurance fund based on the Balanced Scorecard. Labor and Social Security World, (2).

Ma, Y. (2006). The management of social insurance fund performance evaluation system construction. Journal of Yunnan Finance and Economic University, 3, 129-131.

Maarse, H., Paulus, A., \& Kuiper, G. (2005). Supervision in social health insurance: A four country study. Health Policy, 71(3), 333-346. http://doi.org/10.1016/j.healthpol.2003.12.017

Office, U. S. G. A. (2003). Performance budgeting: Current developments and future prospects. Government Accountability Office Reports (May).

Sun, C. Y. (2013). Research on Performance Auditing Evaluation of social insurance fund. Southwestern University of Finance and Economics.

Xu, Y. L. (2011). Performance management theory, method, process and application. Beijing, BJ: Economic Science Press.

Yan, C., \& Wei, Q. J. (2010). Study on the performance evaluation technology process of social insurance fund. China Township Enterprise Accounting, 1, 22-23.

Yan, J., Bai, H., \& Lin, R. B. (2004). The Balanced Scorecard Application. Beijing, BJ: Haitian press.

Yang, C. J. (2010). Evaluation mechanism of social insurance fund management performance in China. Southwestern University of Finance and Economics.

Yu, N. (2012). Research on the performance evaluation index system of basic pension insurance funds. Journal of Social Science, 6, 87-94. http://dx.doi.org/10.13644/j.cnki.cn31-1112.2012.06.010

Zhang, Z. C., \& Ding, H. (n. d.). Performance evaluation methods and implications of the social security administration of the United States. Financial and Economic Research, 6, 77-81.

Zhu, D., \& Cheng, Y. (2008). Weight design of performance evaluation index of social insurance fund. Journal of Central University of Finance and Economics, (8), 45-49.

\section{Copyrights}

Copyright for this article is retained by the author(s), with first publication rights granted to the journal.

This is an open-access article distributed under the terms and conditions of the Creative Commons Attribution license (http://creativecommons.org/licenses/by/4.0/). 